\title{
Spinozảs Parallelism Doctrine and Metaphysical Sympathy
}

Karolina Hübner

\begin{abstract}
By what natural connection and as it were harmony and mutual agreement, which the Greeks call sympathy, can there be coordination between the fissure in a liver and my small fortune, or between my small profit and heaven, the earth, and the nature of things?

(CICERo, Divination 2.33-34)
\end{abstract}

\section{INTRODUCTION}

There are many different ways one can think about the notion of cosmic "sympathy." In this chapter I want to approach this idea as a thesis of a fundamental connectedness of all things-a connexio rerum — and show how this ancient idea is rehabilitated in the metaphysics of an early modern thinker, Baruch Spinoza (1632-77). More precisely, I want to show that the ancient idea of cosmic "sympathy," reinterpreted in accordance with Spinoza's demand for universal intelligibility, illuminates key doctrines of his metaphysics, and in particular his conceptions of identity and of the relation between thought and being. ${ }^{2}$

I Thanks to the volume editors and to the participants of the "Sympathy" conference at the University of Richmond, especially Eric Schliesser, for invaluable comments on an earlier version of this essay.

2 For an account of how Spinoza understands sympathy in his ethics, see chapter 6 in this volume. 
Admittedly, one may be surprised to find Spinoza and "sympathy" as bedfellows. For one might have expected that the advent of mechanism as the dominant explanatory paradigm in the early modern period had rendered the idea of cosmic sympathy "occult," and hence philosophically illegitimate, for most thinkers. Prima facie sympathetic relations between things seem irreducible to explanations in terms of size, shape, and motion alone, as mechanism demands. Likewise, sympathetic action at a distance seems to evade the basic mechanistic requirement that there be contact between bodies for action to occur.

In fact, however, many early moderns did not reject the notion of "sympathy" tout court. Instead, they undertook to better explain the phenomena that had been deemed "sympathetic" by their predecessors, and to reduce allegedly sympathetic relations to mechanistic ones. ${ }^{3}$ And so for example Descartes-arguably Spinoza's most important intellectual precursor-writes,

I have deduced the causes - which I believe to be quite evident-of these and many other phenomena from principles which are known to all and admitted by all, namely the shape, size, position and motion of particles of matter. And anyone who considers all this will readily be convinced that there are no powers in stones and plants that are so mysterious, and no marvels attributed to sympathetic and antipathetic influences that are so astonishing, that they cannot be explained in this way. ${ }^{4}$

\footnotetext{
3 For an example of early modern resistance to such mechanistic reduction of sympathetic phenomena see Henry More, Immortality of the Soul, ed. A. Jacob (Dordrecht: Martinus Nijhoff, 1987), 3.5.I.

4 René Descartes, Principles of Philosophy, in The Philosophical Writings of Descartes, ed. and trans. John Cottingham, Robert Stoothoff, and Dugald Murdoch (Cambridge: Cambridge University Press, 1985), vol. I, 4.187, AT 8A.314. Cf. "The sciences, however abstruse [occultae], are to be deduced only from matters which are easy and highly accessible, and not from those which are grand and obscure.... To inquire whether a natural power can travel instantaneously to a distant place... I shall not immediately turn my attention to the magnetic force, or the influence of the stars.... I shall, rather, reflect upon the local motions of bodies... readily perceivable.... [N] or shall I prattle on about the moon's warming things by its light and cooling them by means of some occult quality. Rather, I shall observe a pair of scales" (Descartes, Rules for the Direction of the Mind, in Philosophical Writings, vol. I, rule 9 , AT 10.402).
} 
In similar spirit, Hobbes (another major influence on Spinoza) tries to explain magnetism - the sympathetic phenomenon par excellenceby reference to infinitesimal motions of bodies: "the attractive power of the loadstone is nothing else but some motion of the smallest particles thereof"; hence appealing to "sympathy" is "to no purpose."

This kind of deflationary attempt to integrate elements of ancient thought within a modern framework is also, as is well known, one of the hallmarks of Spinoza's thought. Spinoza systematically reinterprets received doctrines-what, he puts it, others saw but only "as if through a cloud" - in accordance with the demands of what he takes to be truly "adequate" thought: timelessly true descriptions of the essences and properties of things. ${ }^{6}$ In Spinoza's system, the newfangled mechanistic physics is thus made to coexist with a Platonic, emanative metaphysics, as well as, as is often emphasized, with a neo-Stoic ethics. ${ }^{7}$

5 Thomas Hobbes, De Corpore 4.26, 30.

Leibniz's notion of a "pre-established harmony" among the perceptions of causally isolated substances can also be seen as an attempt to rehabilitate the idea of a sympathetic connectedness of all things. See e.g. his claim that "pre-established harmony ... between all the monads or simple substances ... takes the place of that untenable influence of the one on the others" (Gottfried Wilhelm Leibniz, New Essays on Human Understanding, ed. and trans. Peter Remnant and Jonathan Bennett [Cambridge: Cambridge University Press, 1996], 296). See also "Discourse on Metaphysics," 33 (Philosophical Essays, ed. and trans. Roger Ariew and Daniel Garber [Indianapolis: Hackett, 1989]). See also David Hume's invocation of physical sympathy in A Treatise of Human Nature, ed. David Fate Norton and Mary J. Norton (New York: Oxford University Press, 2000), 3.3.1.7.

On Leibniz and sympathy, see Christia Mercer, Leibniz's Metaphysics: Its Origins and Development (Cambridge: Cambridge University Press, 2001), 193-94, 354-55, and chapter 4 in this volume. For a general overview, see Brian Copenhaver, "The Occultist Tradition and Its Critics," in The Cambridge History of Seventeenth-Century Philosophy, ed. Daniel Garber and Michael Ayers (Cambridge: Cambridge University Press, 1998), 1.455-512.

6 Baruch Spinoza, The Ethics, in The Collected Works of Spinoza, ed. and trans. Edwin Curley (Princeton, NJ: Princeton University Press, 1984), 2p7s; rapp (II/79); 2p44c2. In citing from Curley's translation of Spinoza's Ethics, I use the following standard abbreviations: $\mathrm{ax}=$ axiom, def $=$ definition, $\mathrm{p}=$ proposition, $\mathrm{d}=$ demonstration, $\mathrm{s}=$ scholium, $\mathrm{c}=$ corollary, app $=$ appendix, pref $=$ preface. "NS" refers to the posthumous 1677 Dutch edition of Spinoza's writings, De Nagelate Schriften van B.D.S.

Cf. Leibniz's comments about "restoring" and "rehabilitating" the Aristotelian "substantial forms" "in a way that would render them intelligible, and separate the use one should make of them from the abuse that has been made of them" ("New System of Nature," in Philosophical Essays, 139).

7 Ethics II/97-I03; IpI7s[I] (II/62); 4app32 (II/276). On Spinoza's emanationist framework see e.g. Martial Gueroult, Spinoza (Paris: Aubier-Montaigne, 1968), 1.246-97; and Valtteri Viljanen, "Spinoza's Essentialist Model of Causation," Inquiry 51.4 (2008): 412-37. On Spinoza's Stoic influences see e.g. Susan James, "Spinoza the Stoic," in The Rise of Early Modern Philosophy: The Tension between the 
Although this is not usually noted, Spinoza was familiar also with the ancient concept of cosmic "sympathy." The term appears in his writings as a label for relations and processes in nature that appear to us as less than fully intelligible, insofar as we cannot fathom their underlying causes. Thus Spinoza writes, for example, "it can happen that we love or hate some things without any cause known to us, but only (as they say) from Sympathy or Antipathy [sympathia ...et antipathia]." In other words, from Spinoza's point of view, to see sympathy as a force operative in nature is just to fail to grasp the causes of things.

Spinoza famously describes this kind of knowledge of effects alone as a knowledge of "conclusions without premises." For him, as for most ancient and early modern philosophers, causes are the key to intelligibility: things are what they are, and have the properties they do, because of their causes. So to adequately know any thing we must know the causes that necessitate its existence and properties. ${ }^{10}$

Spinoza's fundamental commitment to universal intelligibility is today often referred to by scholars as his commitment to the Principle of Sufficient Reason (PSR), and I will adopt this shorthand in what

New and the Traditional Philosophies from Machiavelli to Leibniz, ed. Tom Sorrell (Oxford: Oxford University Press, 1993), 289-316.

8 Ethics 3pi5s (II/I52), emphasis added. Spinoza also mentions metaphysical "sympathy" in his early manual on Descartes's philosophy, when he notes that Descartes's commitment to a "real distinction" between parts of matter shows that "Sympathy and Antipathy are to be rejected as false" (Descartes' Principles of Philosophy, in Collected Works, 2p8s; I/197). Of course in his own philosophy Spinoza rejects the Cartesian thesis that parts of matter are really (as opposed to merely modally) distinct from one another-as well as the idea that real distinction corresponds to a numerical distinction between substances (cf. Ethics ipios).

9 Ethics 2p28d.

Io Cf. "The knowledge of an effect depends on, and involves, the knowledge of its cause" (Ethics rax4). There is much controversy about whether Iax 4 applies to adequate knowledge only. In this essay I assume that the axiom applies at least to adequate knowledge, such that to know a thing adequately (or, equivalently, to make it fully intelligible) we need to grasp its causal dependencies. On the problem of the axiom's scope see e.g. Margaret Wilson, "Spinoza’s Causal Axiom (Ethics I, Axiom 4)," in Ideas and Mechanism: Essays on Early Modern Philosophy, by Wilson (Princeton, NJ: Princeton University Press, 1999), I4I-65.

Such perfect causal knowledge of things is not only Spinoza's epistemic ideal; it is also something he believes to be already given in nature, insofar as all things are eternally adequately conceived by God's "infinite intellect." See Ethics 2p3, 2p7c. 
follows. ${ }^{11}$ This commitment to the PSR means that Spinoza's metaphysics will be thoroughly hostile to any phenomenon or law of nature that would in principle be inexplicable. ${ }^{12}$ The commitment also means that natural phenomena that once may have been deemed "sympathetic" - that is, phenomena that, on Spinoza's diagnosis of "sympathy," are known to us only through their effects-have to be either simply eliminated from metaphysics or made fully intelligible. That is, a Spinozist must either uncover the causes on which purportedly "sympathetic" effects depend (thus making the influences in question intelligible) or show that it is metaphysically impossible for a causal relation to hold in a particular case. (For example, one of Spinoza's basic metaphysical principles is that relations of causal dependence are possible only within the boundaries of the same kind of being. ${ }^{13}$ That means, for instance, that only bodies can enter into causal relations with bodies, and only minds can enter into causal relations with minds. As a result, for Spinoza, any putative "sympathetic" influence that crosses from the mental realm to the corporeal realm, or vice versa, will turn out to have been illusory. $)^{14}$

II Ethics Iax2, ipıraltdr. For a discussion of the role of PSR in Spinoza's philosophy see Michael Della Rocca, Spinoza (London: Routledge, 2008), and "Rationalist Manifesto: Spinoza and the Principle of Sufficient Reason," Philosophical Topics 31.I-2 (2003): 75-94.

I2 This is so even though Spinoza allows both that it is not within the powers of finite human minds to grasp the entire series of finite causes leading up to any particular phenomenon and that there are entire realms of nature-those that are neither mental nor physical-that are in principle excluded from being known by human minds. See Spinoza, Treatise on the Emendation of the Intellect, in Collected Works, [100], Ethics 2ax5, and The Letters, trans. Samuel Shirley, ed. Steven Barbone, Jonathan Adler, and Lee Rice (Indianapolis: Hackett, 1995), letter 66. For discussion of the letter see Yitzhak Melamed, "Spinoza's Metaphysics of Thought: Parallelisms and the Multifaceted Structure of Ideas," Philosophy and Phenomenological Research 86.3 (2012): 636-83.

13 Ethics гр3, грго, 2p5-6.

I4 As we have seen, Spinoza identifies purportedly "sympathetic" relations with misconstrued causal relations. But could some noncausal relation be responsible for the purported sympathetic influence crossing from one realm of being to another? In addition to causal relations, in his metaphysics Spinoza recognizes also conceptual relations, relations of inherence (see e.g. Ethics Idef 3,5 ), relations of intentionality and ontological dependence (2 2 II, 13), and, finally, relations of numerical identity (2p7s). Let's take these one by one. Inherence relations are coextensive with, and perhaps even identical to, causal relations. Hence ruling out the possibility of causal relations in a particular case also rules out the possibility of inherence relations. Conceptual relations are, like causal relations, subject to the principle of closure of kinds of being, such that only mental things can help us cognize other mental things. Hence they also could not be responsible for cross-realm influence. 
Spinoza thinks that an adequate understanding of nature will show it to be a genuine unity, grounded in a single, thoroughly deterministic causal power. ${ }^{15}$ But, he also thinks, for the most part we fail to understand this: we fail to understand not only the causal mechanisms at work around us but equally the fact that every one of our own actions and appetites depends on an infinite series of prior causes. This failure, Spinoza proposes, is precisely what's behind our long-standing, but erroneous, belief in "free will" where "freedom" is understood as the absence of determination. ${ }^{16}$ More generally, our ignorance of the nature of causal relations leads us to see nature as a realm of merely "sympathetic" influences between discrete beings, each one a "conclusion" detached from its "premises."

In one sense then, thinking of nature in terms of "sympathetic" relations is from Spinoza's point of view simply an error, analogous to thinking of ourselves as endowed with free (undetermined) will. But Spinoza's vision of the fundamental unity of nature, and in particular his belief that all finite things are just modifications of one fundamental entity, also makes him particularly well suited to the task of rehabilitating the notion of cosmic "sympathy." That is, my suggestion is that in a Spinozistic context "sympathy" does not have to be understood merely pejoratively, as a symptom of our causal ignorance. This, to be sure, is how Spinoza himself uses the term. But in addition to this explicit and negative discussion of sympathy, in Spinoza's writings there is alsoand more importantly in my view-an implicit rehabilitation of the idea of cosmic sympathy. In Spinoza's version, the doctrine of sympathy is a metaphysical doctrine of the fundamental relatedness and unity of all beings, a fully intelligible (according to Spinoza's standards

\footnotetext{
However, it seems possible in principle that a particular allegedly "sympathetic" relation may have been a way of confusedly recognizing that a given mind and a given body are in fact numerically identical (as Spinoza holds [Ethics, 2p7s]), or perhaps that minds ontologically depend on bodies they represent (2PII, I3).

I5 Ethics Iр16, гр26, Iр28-29, Iр34. Indeed, more precisely, Spinoza is not just a determinist but a necessitarian.

${ }_{16}$ See Ethics rp28, rapp (II/78-79), 2p48, 3p7d, 3p9s, 4 pref (II/207), $4 \mathrm{def} 7$.
} 
of intelligibility) connexio rerum ultimately rooted in Spinoza's conviction that in metaphysical rigor there exists only one thing. ${ }^{17}$ This point - that Spinoza makes the doctrine of cosmic sympathy a part of his monistic metaphysics-is the first main claim I want to make in this chapter.

Spinoza discusses the idea of a fundamental connection of all beings at length in one of the most important, and controversial, passages in his magnum opus, the Ethics: in 2p7, its corollary and scholium. As we shall see in what follows, these passages bear not just on the relation between distinct entities but also on the relation between being and thought more generally. The doctrine put forth in these passages is usually referred to as Spinozas "parallelism" doctrine. However, I will avoid this terminology here, for the following reason. As has often been noted, "parallelism" is not a term Spinoza himself employs, and in my view it is at best unhelpfully vague, and at worst outright misleading. The word "parallelism" suggests mere correspondence, or some sort of isomorphism. ${ }^{18}$ In fact, however, as we shall see, the fundamental relations at stake in the passages in question-in 2p7, its corollary, and scholium—are relations of identity and unity. (Other scholars have argued that the term "parallelism" is misleading because it suggests the presence of a single doctrine while in fact $2 \mathrm{p} 7$ and its scholium advance two distinct doctrines, one concerned with representation, and the other with identity: a blind or ontological parallelism to be distinguished from a representational or epistemological

I7 However, Spinoza would, to be sure, be wary of describing nature as "harmonious," as some advocates of cosmic sympathy do. According to Spinoza such predicates as "harmonious" tell us nothing about things as they are in themselves, only about how they happen to affect us at a particular time or place (see Ethics rapp; II/78). Given his well-known criticisms of cosmic teleology (ıapp; 4pref, 3p7d, $4 \mathrm{def}_{7}$ ), Spinoza would be equally wary of thinking of sympathetic relations among things as if these served some cosmic end nature as a whole could have, as Plotinus for example does.

I8 Unfortunately, all too often scholars merely gloss "parallelism," rather vaguely, as "mirroring," "correspondence," "isomorphism," "structural similarity," "mapping," "correlation," and "matching," without going into the precise nature of the relation. Melamed is an exception, writing, "I take parallelism to be a relation of isomorphism in the strict sense of the term, i.e., one-to-one and onto mapping. This relation preserves the causal structure among the relata" ("Metaphysics of Thought," 637 n 3 ). 
parallelism. ${ }^{19}$ There are reasons to resist this kind of reading too, as we shall see later.)

This then is the second main claim I will make in what follows: that Spinoza's positive reconception of cosmic "sympathy" as a thesis of a fundamental connectedness of things revolves around relations of identity and unity, especially as understood in terms of the real unity of the single substance.

However, before I can argue for these points in more detail, I need to provide the necessary background: a brief outline of the basic building blocks of Spinoza's metaphysics. This will be the task of the next section. (Readers familiar with Spinoza's metaphysics should feel free to skip directly to section 3.)

\section{BACKGROUND}

The pillar of Spinoza's ontology is his substance monism, or the doctrine that there is only one fundamental entity. This entity, which Spinoza calls the "absolutely infinite substance" or "God," is defined by its existential and conceptual self-sufficiency. ${ }^{20}$ Everything else that existsand according to Spinoza there necessarily exists an "infinity" of things-is merely a dependent property and modification of this fundamental entity. ${ }^{21}$ This sole possible substance and its modifications ("modes") exhaust Spinoza's ontological inventory: they are the only two metaphysically possible kinds of entities. ${ }^{22}$

\footnotetext{
I9 For this reading see e.g. Gilles Deleuze, Expressionism in Philosophy: Spinoza, trans. M. Joughin (London: Zone Books); 113-14; Michael Della Rocca, Representation and the Mind-Body Problem (Oxford: Oxford University Press, 1996), 19, and Spinoza, 90; Alan Donagan, Spinoza (Chicago: University of Chicago Press, 1988), 180; Melamed, "Metaphysics of Thought"; Steven Nadler, Spinoza's Ethics: An Introduction (Cambridge: Cambridge University Press, 2006), 124.

20 Ethics Idef, Idef6.

21 Ethics ids, ipi4-16, ipi8.

22 Ethics ip4d.
} 
Spinoza's conception of substance is perhaps most unorthodox in that Spinoza does not take substance to have a single essential nature. ${ }^{23}$ Substance-and, derivatively, its modifications-possesses multiple, qualitatively heterogeneous essential natures. ${ }^{24}$ Following Descartes, Spinoza calls these natures substance's "attributes." 25 The diversity of attributes are does not contravene the ontological unity of Spinozistic substance: this substance is equally essentially a thinking thing and an extended thing (and every other kind of thing, if there are other kinds of being, inaccessible to human minds). The same is true, derivatively, of all its finite properties: each is at least a mind and a body.

Spinoza identifies each of substance's attributes by means of one principal concept: "thought," "extension," and so on. Each of these concepts represents the property that all things of this particular kind, and only of this kind, presuppose for their explanation. ${ }^{26}$ (For example, explanation of any particular idea, volition, or doubt presupposes our use of the concept of "thought," but not that of "extension" for instance; all explanation of bodies, movements or rests presupposes the use of the concept "extension" but not "thought.") As a consequence, different attributes by definition have no common conceptual denominator in any relevant sense. ${ }^{27}$ Given Spinoza's commitment to universal intelligibility, entities under different attributes-for example, a particular body and a particular mind-thus cannot enter into causal relations. ${ }^{28}$ This is because, in the absence of a shared conceptual sphere, such an event would be in principle inexplicable. For this reason, in Spinoza's eyes such an event is therefore also metaphysically

\footnotetext{
23 See in contrast Descartes, Principles, I, 53.

24 Ethics Idef6, 2 pi-2.

25 See Descartes, Principles, I, 53.

26 Cf. Descartes, Principles, I, 53.

27 It would be more accurate to say that what different attributes do have in common they have in common in the wrong way: abstractly of course all attributes have that in common that they can be classed together under universals like "attribute" or "expression." (For a fuller account of abstraction and universals in Spinoza's metaphysics see Karolina Hübner, "Spinoza on Essences, Universals and Beings of Reason," Pacific Philosophical Quarterly, forthcoming.)

28 Ethics ip3, rрio, 2p5-6.
} 
impossible. All causal connections have to be underwritten by conceptual connections.

\section{ConNexio RERUM}

With this sketch of Spinoza's basic metaphysical framework in place, let me now turn to what I want to claim is his reinterpretation of the sympathetic connexio rerum in terms of fully intelligible relations of unity and identity.

Spinoza's key pronouncement on the subject of the connectedness of things in nature can be found, as noted earlier, in 2p7 and associated passages. It begins as follows:

The order and connection of ideas is the same as the order and connection of things [Ordo et connexio idearum idem est ac ordo et connexio rerum].

Dem.: This is clear from rax4. For the idea of each thing caused depends on the knowledge of the cause of which it is the effect. (2p7)

Spinoza manages to compress many ideas into these few short sentences. Let me take them one by one, starting with the notion of an "order and connection" of things. ${ }^{29}$

The demonstration to $2 \mathrm{p} 7$ makes clear that the "connection of things" described in the proposition is supposed to be understood as a connection of things qua causes. That is, the connexio rerum at stake here is a connection of things standing in relations of causal dependence. Now, if we draw on what Spinoza says elsewhere in the Ethics, we can characterize the nature of this causal connectio rerum a bit more precisely, and thus also understand why for Spinoza a connection of "things" is equivalent to a causal connection.

\footnotetext{
29 Since for Spinoza there seems to be no significant difference between the notions of "order" and "connection"-in 2p7s (II/90) and 3p2s (II/I4I), for example, Spinoza suggests their synonymityI will use them interchangeably in what follows.
} 
We should thus recall, first, that in Spinoza's view all things (including substance) have causes (more precisely, all things, including substance itself, are causally dependent on substance insofar as they are the necessary consequences or implications of its essence). ${ }^{30}$ In particular, each finite thing depends on prior members of an infinite series of finite causes. ${ }^{31}$ (In other words, a finite thing's causal dependence on substance is mediated by its dependence on other finite things.)

Second, for Spinoza every "thing" also is a cause (as he puts it, "Nothing exists from whose nature some effect does not follow"). ${ }^{32}$ So modes are not merely substance's effects; more precisely, they are effects by means of which substance brings about still further effects.

Now, to assert that all "things" both are and have causes is tantamount to saying that only what can enter into causal relations has being or metaphysical "reality." ${ }^{33}$ Hence, for Spinoza, a comprehensive characterization of causal relations in nature will include in its scope all entities: the "causal order of nature" is extensionally the same as the "connection of things."

I suggest that this causal sense of connexio rerum is the first sense in which all things in nature are fundamentally connected in Spinoza's view-the first sense in which there is something like cosmic metaphysical sympathy. ${ }^{34}$ The in-principle intelligibility of this connexio rerum is guaranteed simply by the existence of the things' causes. In the case of finite things, their dependence on an infinite series of prior causes also means that no finite thing can be truly known apart from other finite things. In this sense for Spinoza, as for many earlier advocates of cosmic

30 Ethics Idefi, Ip16, Iax3, Ip25, Ip28. Substance can be described as causally dependent on itself in the sense that its existence follows necessarily from its essence.

31 Ethics ip28. It is only this whole infinite series that is an immediate consequence of substance's essential nature; cf. Charles McCracken, "Knowledge of the Soul," in The Cambridge History of Seventeenth-Century Philosophy, ed. Daniel Garber and Michael Ayers (Cambridge: Cambridge University Press, 1998), 796-832, at 816 .

32 Ethics 1 196.

33 See Ethics 2 def6.

34 Contrast this with Leibniz's noncausal rehabilitation of sympathy as preestablished harmony (see footnote 5 above). 
sympathy, things that prima facie appear distinct and distant can be shown to be in metaphysical rigor causally and explanatorily related.

\section{ConNexio IDEARUM}

So much for how Spinoza understands the "connection of things" in nature. But 2p7 also bears on the connection of ideas. More precisely, the proposition describes the connection of ideas as the "same" as the connection of things. This raises at least two questions: (I) How are we to understand the notion of a connexio idearum? And (2), in what sense exactly is this connexio idearum the "same" as the connexio rerum?

To begin finding answers to these questions, we should note first of all that Spinoza understands the nature of "ideas" ("thoughts," "concepts," "cognitions"-all equivalent terms in his view) quite differently from what we today might understand by these terms. In part this is because Spinoza regards thought as a universally predicable property: all natural things— pebbles, dragonflies, trees—are in his view "minded" or "animate" (even if the "thinking" in which all these disparate "minds" engage is characterized by very different degrees of complexity and autonomy). ${ }^{35}$ As a consequence, from Spinoza's point of view, what we today may associate with "thinking" is not the whole of thinking, nor the essence of thinking, but instead only our experience of the degree of thinking proper to finite human minds-the sorts of ideas that we can be determined to produce. The properly Spinozistic vantage point requires us to see thinking as an activity, a causal process, that belongs first and foremost to substance. ${ }^{36}$ All other ideas, including those that constitute human minds, are for Spinoza merely more or less fragmented

35 Ethics 2pi3s. This thesis of universal mindedness follows from Spinoza's controversial identification of a thing's "mind" with God's idea of this thing. With this identification in place, universal mindedness follows straightforwardly from Spinoza's entirely orthodox commitment to divine omniscience (2p3). For further discussion, see Margaret Wilson, "Objects, Ideas, and 'Minds': Comments on Spinoza's Theory of Mind," in Ideas and Mechanism: Essays on Early Modern Philosophy, by Wilson (Princeton, NJ: Princeton University Press, 1999), 126-40.

36 Cf. Melamed, "Metaphysics of Thought," 678. 
and incomplete "parts" of the necessarily true idea formed by this unlimited, cosmic thinking subject. ${ }^{37}$ Whatever metaphysical "connections of ideas" are possible will thus be determined by the order of ideas proper to substance's "infinite idea," veridically representing all that is (namely, substantial essence and all its implications).

The way Spinoza demonstrates 2p7 suggests that the "sameness" of the orders of things and ideas follows immediately from the causal requirement on knowledge, set down in Iax4. The general line of thought here seems clear enough: ${ }^{38}$ if to know a thing requires us to know its causes, then an infallible intellect must represent in its ideas the causal order of things that in fact obtains in nature. So far so good. However, this might lead us to conclude further that when Spinoza asserts that ideas depend on one another in the "same" way that things do, he is saying that substance as a perfect knower reproduces or mirrors in the relations among its ideas the relations of causal dependence that obtain among things in nature. ${ }^{39}$ That is, we could read Spinoza's claims as an implicit endorsement of some version of the correspondence theory of truth.

It is tempting, furthermore, to add here that Spinoza must have had in mind here a purely logical order of ideas, constituted by relations of entailment or inference among propositions. On this kind of reading, 2p7 would assert the existence of some sort of isomorphism or correspondence of the causal order of things with a purely logical order of ideas.

37 Ethics 2pirc, 2p33, 2p35.

38 If little more than the general line of thought: the brevity and purported self-evidence of this demonstration have caused much consternation among scholars. For discussion see e.g. Jonathan Bennett, A Study of Spinoza's Ethics (Indianapolis: Hackett, 1984), 127; Della Rocca, Representation, 22; Wilson, "Causal Axiom," 153. As has often been noted, for the demonstration of 2 p7 to go through, we must arguably assume also 2p3, i.e., the existence of ideas of all things. See e.g. Edwin Curley, Behind the Geometrical Method: A Reading of Spinoza's Ethics (Princeton, NJ: Princeton University Press, 1988), 64; Deleuze, Expressionism, 114-15; Della Rocca, Representation, 22-23; Wilson, "Causal Axiom," I54.

39 Note the added complication that Spinoza seems to hold that God's infinite idea is simple. It's not clear in what way a simple idea could reflect the causal order among things in nature. 
This is in fact a very common reading of Spinoza. ${ }^{40}$ But there are good reasons to demur. ${ }^{41}$ The biggest problem with such interpretations of the Spinozistic connexio has to do with the "sameness" of the causal order of things and the order of ideas, asserted in 2p7. Let's assume, as most scholars do, that this "sameness" of the two orders amounts to some sort of isomorphism, "mirroring," or "correspondence" of causal dependence relations in nature and entailment relations between propositions. The problem is that classical models of inference fail to mirror in the desired way the relations of causal dependence that Spinoza regards as metaphysically possible. ${ }^{42}$ That is, if we assume that in Spinozistic nature effects "follow" from their causes along the lines of either material or strict implication, we end up attributing to Spinoza causal views he cannot hold. Take, for example, the proposition "God exists." For Spinoza this is a necessarily true proposition. As a true proposition, it is materially implied by any proposition; as a necessary proposition, it is strictly implied by any proposition. So if either of these models of inference mirrored Spinozistic relations of causal dependence, Spinoza would have to be committed to the view that God's existence is caused by the existence of any thing. But it is a fundamental tenet of Spinoza's system that God is causa sui: his existence follows from his essence alone. ${ }^{43}$

40 See e.g. Bennett's claim that for Spinoza "a cause relates to its effect as a premiss does to a conclusion which follows from it" (Study, \$8.3); cf. Edwin Curley: "Spinoza assimilates the relation of causality to the relation of logical implication” (Spinoza's Metaphysics: An Essay in Interpretation [Cambridge, MA: Harvard University Press, 1969], 45-46).

This paragraph is developed more fully in Karolina Hübner, "On the Significance of Formal Causes in Spinoza's Metaphysics," Archiv für Geschichte der Philosophie, 2015.

4I One rudimentary difficulty for this sort of reading is that Spinoza does not seem very interested in logic, and has nothing to say about the nature of inference in particular (cf. Donagan, Spinoza, 74-75). The little he does say on related topics suggests that like many other seventeenth-century thinkers, he thought of logic as a normative and therapeutic "art" akin to medicine (see Ethics 5 Pref [II/277], CM I $[\mathrm{I} / 233])$. That is, he does not belong to that philosophical tradition for which logic is concerned with being qua known. So logical relations would be a rather poor candidate for constituting an order capable of being the "same" as the causal order of things. See Spinoza, Treatise on the Emendation of the Intellect [9r]. 42 To my knowledge Don Garrett was the first to point out this difficulty; his own solution to the problem is to appeal to relevance logic ("Spinoza's Necessitarianism," in God and Nature: Spinoza's Metaphysics, ed. Yirmiyahu Yovel [Leiden: Brill, 1991], 97-118, at 194). See also Della Rocca, "Manifesto," 81, 92 n. I2.

43 Ethics Idefi. 
In short, there are reasons to hesitate before identifying the Spinozistic "connection of ideas" simply with stand-alone entailment or inference relations among propositions, at least as classically understood. Minimally, we would have to restrict in some way the set of relevant entailment relations, so as to prevent inferences to what for Spinoza are metaphysically impossible causal dependencies. One plausible solution here is to introduce a prior metaphysical constraint restricting the set of the conceptual relations under consideration to entailment relations between (the definitions of) things' essences and the properties implied by those essences. This, I suggest, supplies the missing metaphysical constraint on which relations of conceptual dependence, among all those possible on classical models of inference, can genuinely be the "same" as causal relations obtaining in Spinoza's nature: namely, only those that hold between the substantial essence and the properties its definition analytically contains, and between the essences of those properties and their properties. (To return to the case we were considering above, this prior metaphysical constraint rules out for example the possibility of deriving substantial existence from truths about modes.)

We have then the beginnings of an answer to the question of how to interpret the notion of a "connection of ideas" within Spinoza's metaphysical framework: the ideas being "ordered" or "connected" are, in the first place, ideas produced by substance as a thinking thing; and, second, the "order" or "connection" in question is, at least on one plausible reading, the logical order of entailments from the essences of things to their properties.

Do we want to endorse the further claim that the connexio rerum and the connexio idearum are the "same" in the sense that they "correspond" to or "mirror" one another? Again, there are reasons to hesitate. For merely to assert the existence of some sort of a correspondence hardly sheds more light on the problem. In what sense could such two, prima facie entirely heterogeneous, sorts of relations-relations of causal dependence on the one hand and conceptual relations of essential 
implication on the other-be judged to have one and the same order $?^{44}$ Should we opt here for an idealist reading, on which the connexio rerum and the connexio idearum are the "same" just in the sense that there is really only one order, that of ideas? On such a reading, to be a "thing" would be reducible to being conceived. Unfortunately, this kind of reading seems inconsistent with Spinoza's explicit commitment to multiple kinds of beings, including an "extended" nature conceivable "through itself," and thus, it would seem, precisely not in terms of thought. ${ }^{45}$

Another, more plausible, interpretative possibility here is to opt for a reductive reading of the "sameness" of the two orders that operates in the opposite direction, so to speak. On this reading, the order of causes and the order of ideas would be the same just in the sense that relations of ideas would reduce to causal relations between things: ${ }^{46}$ the "connection" of ideas is given by the order of their causal dependence on one another as things. This interpretation is encouraged by the fact that for Spinoza "thing" is a perfectly general ontological category, and as such includes ideas in its extension. ${ }^{47}$ It also has the explanatory

44 Margaret Wilson for instance glosses the "sameness" in terms of a single "relation of necessary determination" that obtains between "physical things" and "cognitiones" alike; but she confesses that this doesn't tell us much about the nature of this relation ("Causal Axiom," 155). Della Rocca suggests that the sameness in question boils down to a "structural similarity," such as having the same "number of immediate effects" (Representation, 18). An Aristotelian would presumably interpret this "sameness" as the adequatio, or formal identity, of the object being known and of the intellect that receives the intelligible form of the object. See also footnote 18 above.

The corollary to $2 \mathrm{p} 6$ states that nonmental "things" are generated according to a principle independent from thought. This means that the order of things cannot be the "same" as the order of ideas because things depend on ideas (as in theologies according to which God models the world on preexisting ideas in his intellect).

45 Ethics idef8, 2p2, rpio. For further criticisms of idealist readings of Spinoza's metaphysics, as advanced by Della Rocca, see Mogens Laerke, "Spinoza's Cosmological Argument in the Ethics," Journal of the History of Philosophy 49.4 (2011): 439-62; and Samuel Newlands, "Thinking, Conceiving, and Idealism in Spinoza," Archiv für Geschichte der Philosophie 94 (2012): 31-52.

46 This seems to be the view in Melamed, "Metaphysics of Thought," 640.

47 This reading is also suggested by a passage in which Spinoza seems to infer from the "sameness" of the two orders that ideas are subject to the causal order proper to things: "the order and connection of ideas (by [2]p7) is the same as the order and connection of causes. Therefore, the cause of one singular idea is another idea, or God, insofar as he is considered to be affected by another idea; and of this also [God is the cause], insofar as he is affected by another, and so on, to infinity" (Ethics 2pgd; emphasis added). 
advantage that it makes self-evident why, and in what sense, relations between ideas must be the same as relations between things: the necessity of this "sameness" follows from the fact that an idea is just a certain kind of "thing." Unlike the correspondence reading, this account is thus not vulnerable to the charge of failing to illuminate the precise sense in which the two orders are the same. For the only limit on our precision in specifying the properties of this shared order is the limit of our understanding of Spinozistic causality more generally. ${ }^{48}$

\section{Connexio Rerum as IDENTITy}

We can shed still more light on the alleged "sameness" of the order of ideas and the order of things in Spinoza's metaphysics if we draw on a different source-namely, on the Scholastic and Cartesian distinction between "formal" and "objective" reality. Consider the corollary that Spinoza appends to 2 p7, immediately following the demonstration: "From this it follows that God's [NS: actual] power of thinking is equal to his actual power of acting. i.e., whatever follows formally from God's infinite nature follows objectively in God from his idea in the same order and with the same connection." "[quicquid ex infinita Dei natura sequitur formaliter, id omne ex Dei idea eodem ordine eademque connexione sequitur in Deo objective ]. ${ }^{49}$ Let me first clarify the terminology used in the passage. The "formal reality" of a thing picks out what this thing is in its intrinsic nature-for example, as an extended thing, or a thinking one. The "objec-

\footnotetext{
48 One might object that Spinoza's habit of modeling causal relations on relations of ideas-in particular, modeling substantial causality on relations of inference of properties from the essences of geometrical figures (see e.g. Ethics ipi7s) - counts against this second reductive reading, insofar as it suggests that the order of ideas constitutes an independent standard by which we can determine how things in nature depend on each other causally. But in fact the most passages like ipi7s entitle us to conclude is that this is how in Spinoza's view we can grasp the nature of causal relations. This is a matter of the order of knowing, and perhaps even solely of Spinoza's pedagogical strategy.

On the import of Spinoza's geometric analogies for Spinoza's causal picture see e.g. Bennett, Study, \$8.3; John Carriero, “Spinoza’s Views on Necessity in Historical Perspective," Philosophical Topics 19.I (1991): 47-96; Curley, Spinoza's Metaphysics, 45-46; Gueroult, Spinoza, 246-97; Viljanen, "Essentialist Model"; Hübner, "Formal Causes."
}

49 Ethics 2p7c. 
tive reality" of a thing refers in turn to what this thing is insofar as it is represented in thought. For example, the sun as a thing existing in nature possesses certain physical properties, a certain mass and size among them. These belong to its formal reality. But the sun exists not only in nature, as a particular, formally real body, but also, whenever some intellect represents it, in thought. This objectively real sun also has a certain reality, one proper to intentional objects. To quote Descartes,

if the question is about what the idea of the sun is... we answer that it is the thing which is thought of, in so far as it has objective being in the intellect.... 'Objective being in the intellect'... will signify the object's being in the intellect in the way in which its objects are normally there. By this I mean that the idea of the sun is the sun itself existing in the intellect... in the way in which objects normally are in the intellect. ${ }^{50}$

Spinoza makes this dual conception of metaphysical reality or being part of his system. (Presumably he sees objective reality simply as part of the nature of thought as such - that is, as part of the self-explanatory essence of substance as a thinking thing. $)^{51}$ The twist Spinoza puts on this inherited framework is that Spinozistic formal reality comes in infinite, or all possible, kinds, rather than only the two-extension and thought-acknowledged by Descartes. And the corollary Spinoza appends to $2 \mathrm{p} 7$ clarifies the nature of the relation between this infinitely varied formal reality (i.e., substance and its modes under all the attributes as things in nature) and the objective reality of substance's "infinite idea" (i.e., the objective reality of substance's perfect representation of its own essence and all its implications). As a perfect knower, substance adequately represents every formally real effect it gives rise to. So whatever has formal reality in Spinozistic nature also has objective reality in substance's idea or representation of this nature. In other

50 Descartes, Author's Replies to the First Set of Objections, in Philosophical Writings, AT 7.103.

5I Hence Spinoza regards as something "known through itself" that truth amounts to "what is contained objectively in the intellect" being "necessarily... in nature" (Ethics Ip3od). 
words, for Spinoza, whatever has any reality at all has at the same time both formal and objective reality.

This is the sense in which substance's two fundamental causal "powers" - the power to think or to produce representations, and the power to "act," or to produce formally real things — are, as Spinoza puts it in the corollary, "equal": the order of ideas (what is represented by substance as an omniscient knower) and the order of things (what is produced by this substance as the universal cause) are "equal" in their respective degrees of reality. ${ }^{52}$ It is a matter of two different, but equal, ways of having being.

The corollary to $2 \mathrm{p} 7$ thus suggests that if we want to think of Spinoza's substance-monistic metaphysics as nonetheless also a kind of dualism, we can draw the dividing line in at least two different places: not just between being and thought, as has been proposed before, ${ }^{53}$ but equally between formal and objective reality. (These two dualisms are orthogonal to one another, since "thought" includes both the objective reality of the ideas' representational content, and the formal reality specific to thought as a causal power proper to substance.)

The corollary also helps us flesh out further the sense of Spinoza's claim in the proposition that the order of ideas is the "same" as the order of things. I proposed above that the two orders can be regarded as the "same" insofar as ideas, like all "things", are causally ordered. The corollary suggests that, in addition, understanding the "sameness" of the orders of ideas and things also involves grasping that everything exists with two kinds of reality: in nature and in the infinite intellect. In this case, the "sameness" of the order of things and the order of ideas amounts to an identity: the identity of every thing, whether substance or mode, as it is in nature, with this thing as it is in the infinite

\footnotetext{
52 Note that in asserting this equality Spinoza departs from Descartes, who treats objective reality as a "mode of being... much less perfect than that possessed by things which exist outside the intellect" (First Replies, AT 7.103).

53 See Melamed, "Metaphysics of Thought," 677-78.
} 
intellect. ${ }^{54}$ We can thus conclude that, in Spinoza's framework, certain relations of identity (of formal with objective realities) must obtain if ideas are to be causally so ordered as to veridically represent the order of things. (And, conversely, ideas must have a certain causal order for those relations of identity to obtain.)

For Spinoza the "sameness" of the orders of being and thought, of the connexio rerum and the connexio idearum, is thus not a matter of a mere correspondence or an isomorphism or a "mapping" of one order onto the other. Likewise, it seems inaccurate to say that the corollary to 2p7 is concerned solely with a "representational parallelism," or with epistemological relations, as opposed to identity, which (it is alleged) Spinoza raises as a concern only in the scholium that follows. ${ }^{55}$ As we have seen, for Spinoza issues of representation are inseparable from matters of ontology: being represented just is having a certain kind of being. To be sure, as has been pointed out before, in the corollary to 2p7 there can be no question of the identity of the relata as formally real, since the whole of formal reality-which includes the "absolutely infinite" substance-cannot be numerically identical with a mere idea representing this substance's essence and its consequences; like any idea, this idea is only a mode. ${ }^{56}$ Nonetheless, the corollary does assert the identity of the formal reality of all that is with the objective reality of the substance's idea: it is one and the same absolutely infinite object taken first in its formal reality and then in its objective reality.

To conclude this discussion of the corollary, let me underscore a more general point. This is that the corollary offers us a unique vantage point onto Spinoza's metaphysics as a whole. Typically this metaphysics gets introduced-as I have done earlier in this chapter-by asserting that there are three fundamental building blocks to this metaphysics

54 Cf. Deleuze, Expressionism, in7. Although the corollary asserts this sameness of order only of the objective reality of ideas (rather than of ideas tout court), I think this is an insignificant difference from the proposition, since in the corollary the order of objective realities is also supposed to be a gloss on substance's "power of thinking" as a whole.

55 For such readings see my footnote is above.

56 See Melamed, "Metaphysics of Thought," 641. 
(substance, modes, attributes), defined so and so, and relating to each other in specific ways. This approach to understanding Spinoza's metaphysics is certainly correct, as far as it goes, and it is encouraged by Spinoza's own manner of presentation in the Ethics, which opens with definitions of such terms. But to consider Spinoza's metaphysics from this perspective is to consider it (to borrow a Heideggerian term) merely "ontically," that is, in terms of what this metaphysics says about entities. ${ }^{57}$ But there is another, equally valid but relatively neglected, approach possible to the foundations of Spinoza's metaphysics: one that defines them not in terms of the kinds of entities it allows but rather in terms of the kinds of being or reality it posits and how it relates them. And seen from this point of view, the crux of Spinoza's metaphysical framework as a whole is the claim that the fundamental "structure" (for lack of a better word) of all that is is given by the fundamental distinctness, but also the unity or inseparability, of formal and objective reality. The corollary to $2 \mathrm{p} 7$ is one place in which this metaphysical picture emerges with particular clarity.

\section{Attributes and Monism}

In conclusion, let me turn to the last passage under scrutiny, the scholium to 2p7. Here is the crucial section:

we must recall here what we showed [NS: in the First Part], viz. that whatever can be perceived by an infinite intellect as constituting an essence of substance pertains to one substance only, and consequently that the thinking substance and the extended substance are one and the same [una eademque] substance, which is now comprehended under this attribute, now under that. So also a mode of extension and the idea of that mode are one and the same thing, but expressed in two

57 See Martin Heidegger, Being and Time, trans. John Macquarrie and Edward Robinson (1927; San Francisco: SCM Press, 1962). 
ways [una eademque est res sed duobus modis expressa].... For example, a circle existing in nature and the idea of the existing circle, which is also in God, are one and the same thing, which is explained through different attributes. Therefore, whether we conceive nature under the attribute of Extension, or under the attribute of Thought, or under any other attribute, we shall find one and the same order, or one and the same connection of causes, i.e., that the same things follow one another [unum eundemque ordinem sive unam eandemque causarum connexionem hoc est easdem res invicem sequi]. ${ }^{58}$

As a rule, the point of the scholium is taken to be the numerical identity of entities differing in attribute (that is, in the essential properties of the kind to which these entities belong). On this reading, the lesson of the scholium is that every mind is, rather paradoxically, numerically identical to some body, and vice versa. ${ }^{59}$

I read the scholium slightly differently. For it seems to me that one of its principal points is to remind the reader, in the wake of a discussion of how things are represented in the corollary and the proposition, of Spinoza's fundamental commitment to substance monism, and thus to the fundamental unity of all things that this monism entails. It is substance monism that determines the sense in which there is, as Spinoza writes above, only one "connection of causes": this is the connection proper to substance, the order of things that follows necessarily from its essence. To put the point slightly differently, the scholium is meant to remind us that whatever can be conceived in the various, attributespecific ways (as thinking substance, as extended substance, as minds, as bodies, and so on) nonetheless constitutes just a single order of thingsa single connection of causes.

In other words, in the scholium Spinoza is cautioning us about what conclusions about the order of formal reality we are entitled to draw

58 Ethics 2p7s, emphases added.

59 See footnote 19 above. Gueroult claims that this identity of entities under different attributes is already asserted in rpi6d (Spinoza, I.339); cf. Melamed, "Metaphysics of Thought." 
on the basis of how ideas are ordered, and the ways they can and cannot connect with one another. More precisely, he is cautioning us that the diverse objective realities of various ideas are not sufficient grounds to conclude that these ideas refer to a numerical plurality of formally real things that would be "really distinct" from one another, as substances are. ${ }^{60}$ For even if we represent thinking things and extended things with the aid of concepts that have nothing in common with one another in the relevant sense, we also must refer all these representations to one and the same formally real entity in nature. ${ }^{61}$

This helps clarify in what sense Spinoza can assert in the scholium that every mind is numerically identical to some body, and vice versa. That is, I do not think that he is putting forth solely a thesis about identity relations directly between modes. Instead, I suggest that when he writes that a mind and a body, or a circle and an idea of that circle, are "one and the same thing," he is reminding us first that they are both identical to the one substance, as its modifications. Every mind and every body, and every circle and idea of a circle, all "pertain to one substance only, just as infinite extension and infinite thought do. Spinoza's point throughout the passage remains the same: don't forget that there is only substance.

This helps us give sense to a relation of numerical identity that would hold between modes of distinct attributes. As has been pointed out before, there is a very rudimentary problem for this interpretation of 2 p7s. The problem is that for any attribute-specific predicates $\mathrm{F}$ and $\mathrm{G}$, we cannot infer from the fact that a given mind is essentially $\mathrm{F}$, or causes some idea to be $\mathrm{G}$, that the body with which this mind is purportedly numerically identical either is F or causes another body to be $\mathrm{G}$. What sense can we then give to the claim that the mind and body in

60 Indeed, Spinoza reduced "real distinction" to the distinction between the various attributes of the one substance (ipros), such that this distinction no longer aligns with a numerical distinction between substances.

6I Hence I also don't think that we should see 2p7s as the "more general" formulation of parallelism, as suggested e.g. by Della Rocca (Spinoza, 91). 
question are "identical," if they fail to share such basic properties $?^{62} \mathrm{I}$ suggest that we not take the scholium to make claims simply about the numerical identity of modes with one another, but instead more fundamentally take it to assert the real identity of modes with substance (where "real identity" just means the absence of real distinction).

Let me close with the following more general remark. As I noted above, it is often claimed that the scholium to $2 \mathrm{p} 7$ is concerned with a different set of problems than the proposition, demonstration, and corollary (in opposition to those who see all these passages as expressing some single and uniform doctrine of "parallelism"). The claim is that the scholium deals with the relation of numerical identity and introduces the subject of the attributes, while the proposition, demonstration, and corollary are silent on all these topics and instead concern themselves solely with representational or epistemological relations. ${ }^{63} \mathrm{I}$ have already raised doubts about the wisdom of separating epistemological and ontological matters in this way within Spinoza's framework. To this criticism I now want to add that those who favor this kind of a "disjunctive" reading of the passages rarely (to my knowledge at least) attempt to explain why Spinoza would append the scholium to the corollary if, ex hypothesi, the two make such distinct claims.

It seems to me that there are two complementary explanations for the existence and placement of the scholium. First of all, as already noted, the scholium functions as a reminder to the reader of how to interpret the import of what our ideas represent within a substance monistic framework. Second, all the passages under consideration, from the proposition all the way to the scholium, are thematically unified around a single metaphysical problem (though it is not the problem of interattribute relations, as Spinoza's "parallelism doctrine"

62 Della Rocca suggests that Spinoza treats causal contexts as referentially opaque, as well as that pairs of identical modes share attribute-neutral properties, such as having the same number of effects (Representation, ch. 7). He also proposes that there is pressure toward the identity of body and mind pairs given their same causal relationships, and a lack of a possible explanation for their nonidentity (Spinoza, 100-101).

63 See my footnote is above. 
is also often glossed). Namely, the thematic unity of all these passages is furnished, as the wording of the proposition itself suggests, by the metaphysical problem of the connection of things in nature-that is, the problem of cosmic sympathy-whether we understand this problem as one of the relation of the two kinds of being, or as the problem of the "real" unity of all things in nature, despite the intellect's apprehension of conceptual gulfs and chasms. 